\title{
Espaçamento e manejo de restos culturais para o controle de Sclerotinia sclerotiorum em feijoeiro
}

\author{
Plant spacing and management of crop residues for control of Sclerotinia sclerotiorum in bean
}

\section{Andreia Maria Faria Macena ${ }^{\mathrm{I}}$ Marcelo Giovanetti Canteri ${ }^{\mathrm{II}}$ Jose Petruise Ferreira Junior ${ }^{\mathrm{II}}$}

\section{- NOTA -}

\section{RESUMO}

\begin{abstract}
A manutenção da camada de palha na superfície do solo e o incremento no espaçamento entrelinhas têm sido difundidos como métodos para o controle de mofo branco. $O$ objetivo deste trabalho foi avaliar a alteração no espaçamento entrelinhas e o manejo da cobertura do solo para o controle de Sclerotinia sclerotiorum na cultura do feijoeiro. O delineamento experimental foi blocos casualizados, em esquema fatorial $2 \times 3$, constituído de seis tratamentos com quatro repetições. $O$ primeiro fator foi o manejo de restos culturais, com dois níveis de manejo (com cobertura e sem cobertura de solo). O segundo fator foi o espaçamento entre linhas, com três níveis $(20,40$ e $60 \mathrm{~cm})$. As variáveis analisadas foram a área abaixo da curva de progresso (AACPD), incidência de mofo branco, números de escleródios, massa de 100 grãos e produtividade. De acordo com os resultados, não ocorreu interação significativa $(P<0,05)$ entre o manejo dos restos culturais e os espaçamentos. Os espaçamentos de 40 e $60 \mathrm{~cm}$ entre linhas foram significativamente superiores a $20 \mathrm{~cm}$ para a redução número de escleródios de $\mathbf{S}$. sclerotiorum, incidência de mofo branco e AACPD. Os parâmetros produtivos não foram afetados significativamente pela variação dos espaçamentos e dos restos culturais.
\end{abstract}

Palavras-chave: cobertura solo, espaçamento entre linhas, incidência de mofo branco.

\section{ABSTRACT}

The methods to control white mold of bean include a layer of straw on the soil surface and the increase in row spacing, aiming to provide disadvantage to the pathogen. The objective of this paper was to assess the change in row spacing and the presence or absence of ground cover (straw) for control of Sclerotinia sclerotiorum in common bean. The experimental design was randomized blocks in factorial scheme $2 \times 3$, consisting of six treatments with four replications. The first factor was the management of crop residues, with two levels of management (with and without coverage of soil). The second factor was the spacing between lines, with three levels (20, 40 and $60 \mathrm{~cm})$. The variables were the area below the disease progress curve (AUDPC), incidence of white mold, sclerotia numbers, weight of 100 grains and yield. There was no significant interaction $(P<0.05)$ between the management of crop residues and spacing. The spacing between rows 40 and $60 \mathrm{~cm}$ were significantly better than $20 \mathrm{~cm}$ to reduce the number of sclerotia of $\boldsymbol{S}$. sclerotiorum, white mold incidence and $A U D P C$. The yield and weight of 100 grains were not affected by variations in the spacing and ground cover.

Key words: soil coverage, seeding density, incidence of white mold.

Os métodos de controle cultural de doenças de plantas consistem na manipulação de práticas visando a criar situação desfavorável ao desenvolvimento do patógeno (REIS \& FORCELINI, 1995). Nesse caso, a manipulação do espaçamento entre linhas e o manejo dos restos culturais têm sido práticas bastante difundidas no controle de mofo branco.

De acordo com NAPOLEÃO et al. (2005), os restos culturais podem funcionar como uma barreira física, impedindo a formação de apotécios e a liberação dos ascósporos de S. sclerotiorum. Apesar de existirem indícios sobre os mecanismos físicos e biológicos que

'Departamento de Fitopatologia, Universidade Estadual de Maringá (UEM), 87260-000, Maringá, PR, Brasil. E-mail: a.faria@hotmail.com

"Universidade Estadual de Londrina (UEL), Londrina, PR, Brasil.

"IIUniversidade Federal de Pelotas (UFPel), Pelotas, RS, Brasil. 
os restos culturais exercem sobre a doença, ainda assim esses mecanismos precisam ser mais bem esclarecidos.

Trabalhos, como os realizados por PAULA et al. (2009), têm comprovado a importância da matéria orgânica na proliferação do fungo Trichoderma spp., antagonistas a S. sclerotiorum. Além disso, resultados obtidos por GORDON (2009) demonstraram redução de $22 \%$ da incidência de $\boldsymbol{S}$. sclerotiorum em cultivo com restos culturais da gramínea (Braquiária decumbens), em comparação com a sua ausência. Alguns trabalhos também têm comprovado que o aumento do espaçamento entre linhas ou a redução na população de plantas diminui a incidência de mofo branco tanto na cultura do feijoeiro (PARK, 1963) quanto em outras culturas, como algodão(SUASSUNA et al., 2009), soja (GRAU \& RADKE, 1984) e girassol (HOES \& HUANG, 1975). De acordo com resultados de BERNARDES (2005), constatou-se uma menor incidência de mofo branco em feijoeiro na densidade de 6 plantas $\mathrm{m}^{-1}$, quando comparados a 12 plantas $\mathrm{m}^{-1}$.

Nesse contexto, o trabalho tem como objetivo avaliar o efeito da variação do espaçamento entre linhas em associação ao manejo dos restos culturais para o controle de $\mathbf{S}$. sclerotiorum.

O experimento foi conduzido no município de Manoel Ribas, PR, em área com histórico de ocorrência do mofo branco nos últimos três anos. As unidades experimentais foram constituídas por parcelas de 4,00m de comprimento por 2,40m de largura, com $4,80 \mathrm{~m}^{2}$ de área útil. A semeadura foi realizada em $11 \mathrm{de}$ outubro de 2009, com equipamento manual "matraca" em espaçamentos de 20, 40 e $60 \mathrm{~cm}$ entre linhas, correspondendo às densidades de 5, 10, e 15 plantas por metro linear. A população final estimada foi de 250.000 mil plantas ha-1 da cultivar 'IAC Alvorada' com hábito de crescimento indeterminado.

O delineamento experimental foi em blocos casualizados em esquema fatorial $2 \times 3$, constituído de seis tratamentos com quatro repetições. $\mathrm{O}$ primeiro fator foi constituído por dois níveis de cobertura vegetal no solo (presença e ausência). No segundo fator, foram três níveis de espaçamento entre linhas (20, 40 e $60 \mathrm{~cm})$. O manejo do solo sem cobertura vegetal constituiu na retirada dos resíduos de trigo antes da semeadura do feijão. Os resíduos vegetais retirados foram peneirados para verificar a presença de escleródio e, quando presentes, foram devolvidos a parcela de origem.

As variáveis analisadas foram número de apotécios, número de escleródios remanescentes na palhada, severidade e incidência e AACPD, massa de 100 grãos e produtividade. Os resultados obtidos foram submetidos à análise de variância pelo teste $\mathrm{F}$ e quando a interação foi significativa foram realizados a análise de regressão e os desdobramentos pelo teste de Tukey em nível de $5 \%$ de probabilidade.

A tabela 1 apresenta os resultados para a análise de variância em delineamento fatorial. Verificouse que não ocorreu interação significativa em nenhuma das variáveis analisadas. Entretanto, no fator espaçamento, houve diferenças significativas para as variáveis números de escleródios, incidência e AACPD.

$\mathrm{O}$ número de escleródios observado no espaçamento $20 \mathrm{~cm}$ foi de 18,8 escleródios $\mathrm{m}^{-2}$, enquanto no tratamento de 40 e $60 \mathrm{~cm}$ observaram-se 14,6 e 14,1 escleródios $\mathrm{m}^{-2}$. Nesse caso, a regressão dos dados de número de escleródios em função do espaçamento (Figura $1 \mathrm{~A})$ foi significativa $\left(\mathrm{R}^{2}=0,84\right)$, ou seja, à medida que aumentou o espaçamento, diminuiu o número de escleródios presentes no solo. Segundo TU (1997), isso ocorre porque o maior espaçamento proporciona maior circulação de ar e diminuição da umidade no dossel, o que desfavorece o desenvolvimento micelial da doença e a consequente formação de escleródios na planta.

O ajuste da regressão para a variável AACPD e incidência (Figura 1B e 1C) apresentou um

Tabela 1 - Quadrados Médios para análise de variância da área abaixo da curva de progresso da doença (AACPD), incidência, números de escleródios, massa de 100 grãos $(\mathrm{M} 100 \mathrm{G})$ e produtividade $\left(\mathrm{kg} \cdot \mathrm{ha}^{-1}\right)$, em resposta à presença e ausência de cobertura do solo (fator A) e da variação do espaçamento entrelinhas (fator B).

\begin{tabular}{|c|c|c|c|c|c|c|}
\hline \multirow{2}{*}{ Fatores de Variação } & \multirow{2}{*}{ G.L } & \multicolumn{5}{|c|}{ 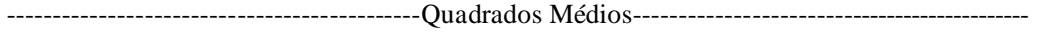 } \\
\hline & & AACPD & Incidência & № Escleródios & M100G & Produtividade \\
\hline Cobertura ( A) & 1 & 1,204 & 0,078 & 10,41 & 0,0938 & 45327,12 \\
\hline Espaçamento (B) & 2 & $38339,1^{*}$ & $13,570^{*}$ & $593,75^{*}$ & 0,0179 & 3427,12 \\
\hline $\mathrm{A} \times \mathrm{B}$ & 2 & 2179,16 & 0,1663 & 102,91 & 0,0013 & 443,04 \\
\hline Bloco & 3 & 6168,05 & 0,0667 & 127,08 & 0,1215 & 11327,04 \\
\hline Resíduo & 15 & 6371,38 & 0,1122 & 184,08 & 0,0562 & 15640,34 \\
\hline $\mathrm{CV}(\%)$ & & 25,92 & 22,07 & 27,03 & 1,06 & 5,49 \\
\hline
\end{tabular}

* Diferenças significativas em nível de 5\% de probabilidade 


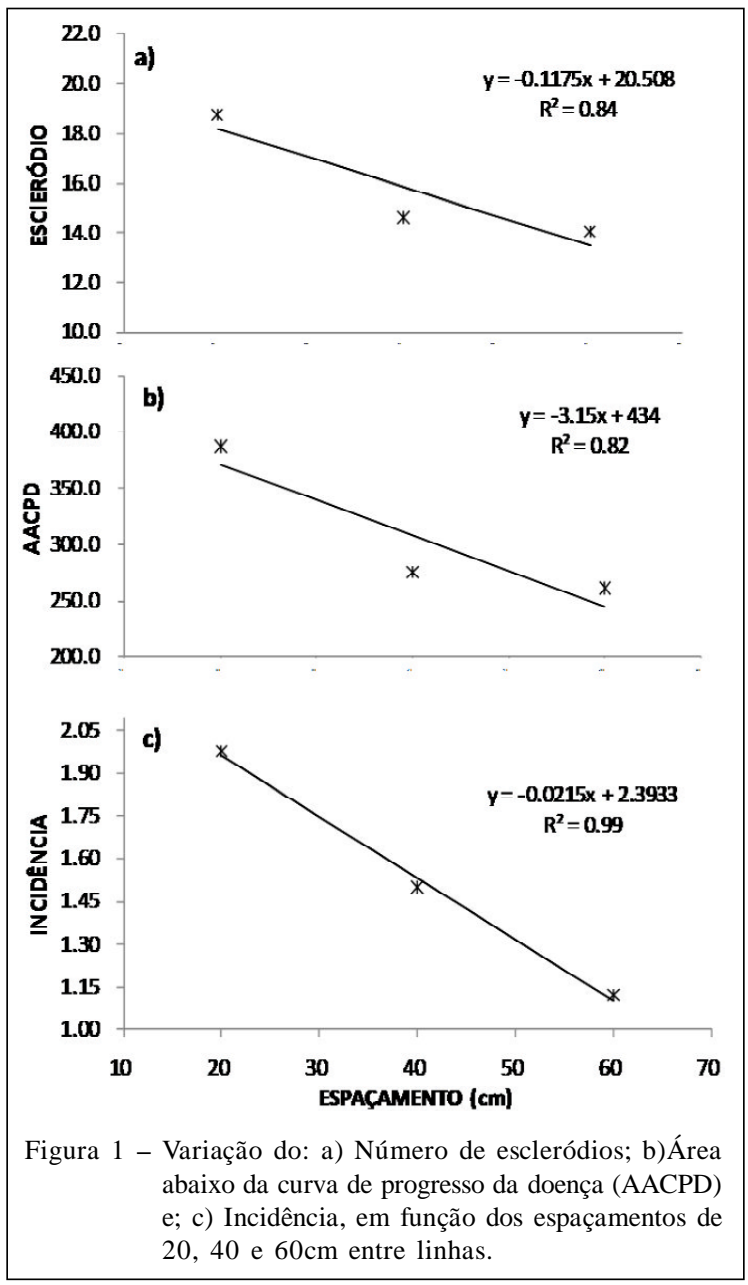

coeficiente de determinação $\left(\mathrm{R}^{2}\right)$ de 0,82 e $\mathrm{R}^{2}=0,99$, respectivamente, portanto, $\mathrm{o}$ aumento no espaçamento propiciou o decréscimo da quantidade de doença. A resposta dos níveis de doença em função da variação do espaçamento pode ser diferenciada de acordo com o genótipo, considerando que os genótipos com hábito de crescimento prostrado exibem maior suscetibilidade à doença (CAMPBEL \& MADDEN, 1990).

O aumento do espaçamento promoveu a redução no número de escleródios, incidência e severidade do mofo branco. A produtividade e a massa de 100 grãos não foram afetadas significativamente
$(\mathrm{P}<0,05)$ pela variação do espaçamento entre linhas e pelo manejo da cobertura do solo.

\section{REFERÊNCIAS}

CAMPBELL, C.L.; MADDEN, L.V. Introduction to plant disease epidemiology. New York: Wiley, 1990. p.230.

BERNARDES, A. Intensidade do mofo-branco do feijoeiro em função da densidade de plantio e da aplicação de Trichoderma spp. 2005. p.40. Dissertação (Mestrado em Fitopatologia) - Curso de Pós-graduação em Agronomia, Universidade Federal de Viçosa, MG.

GRAU, C.R.; RADKE, V.L. Effects of cultivars and cultural practices on Sclerotinia stem rot of soybean. Plant Disease, St. Paul, v.68, n.1, p.56-58, 1984. Disponível em: <http:// www.apsnet.org/publications/PlantDisease/BackIssues/ Documents/1984Articles/PlantDisease68n01_56.pdf>. Acesso em: 01 jul. 2010.

HOES, J.A.; HUANG, H.C. Sclerotinia scleoriorum viability and separation of sclerotinia from soil. Phytopathology, St. Paul, v.65, p.1431-1432, 1975. Disponível em: <http:// www.apsnet.org/publications/phytopathology/backissues/ Documents/1975Articles/Phyto65n12_1431.pdf>. Acesso em: 11 nov. 2010

NAPOLEÃO, R.L. et. Intensidade do mofo branco do feijoeiro em plantio convencional e direto sob diferentes lâminas d'água. Fitopatologia Brasileira, Brasília, v.30, n.4, p.374-379, 2005. Disponível em: <http://www.scielo.br/ scielo.php ? script $=$ sci_art text \& pid = S $0100-$ $41582005000400006 \& \operatorname{lng}=\mathrm{en}^{-} \& \mathrm{nrm}=\mathrm{iso}>$. Acesso em: 01 ago. 2011. doi: 10.1590/S0100-41582005000400006.

REIS, E.M.; FORCELINI, C.A. Controle cultural. In: BERGAMIN FILHO, A. et al. Manual de fitopatologia: princípios e conceitos. 3.ed. São Paulo: Agronômica Ceres, 1995. V.1, p.710-716.

SUASSUNA, D.N. et al. Incidência e severidade de mofo branco em cultivares de algodoeiro com diferentes densidades populacionais no espaçamento adensado em safrinha. In: CONGRESSO BRASILEIRO DE ALGODÃO, 7., 2009, Foz do Iguaçu, PR. Anais... Campina Grande: Embrapa Algodão, 2009. p.966-974.

TU, J. C. Gliocladium virens, a destructive mycoparasite of Sclerotinia sclerotiorum. Phytopathology, St. Paul, v.70, p.670-674, 1980. Disponível em: <http://www.apsnet.org/ publications/phytopathology/backissues/Documents/ 1980Articles/Phyto70n07_670.pdf>. Acesso em: 02 nov. 2010.

VAN DER PLANK, J.E. Plant disease: epidemic and control. New York: Academic, 1963. 349p. 